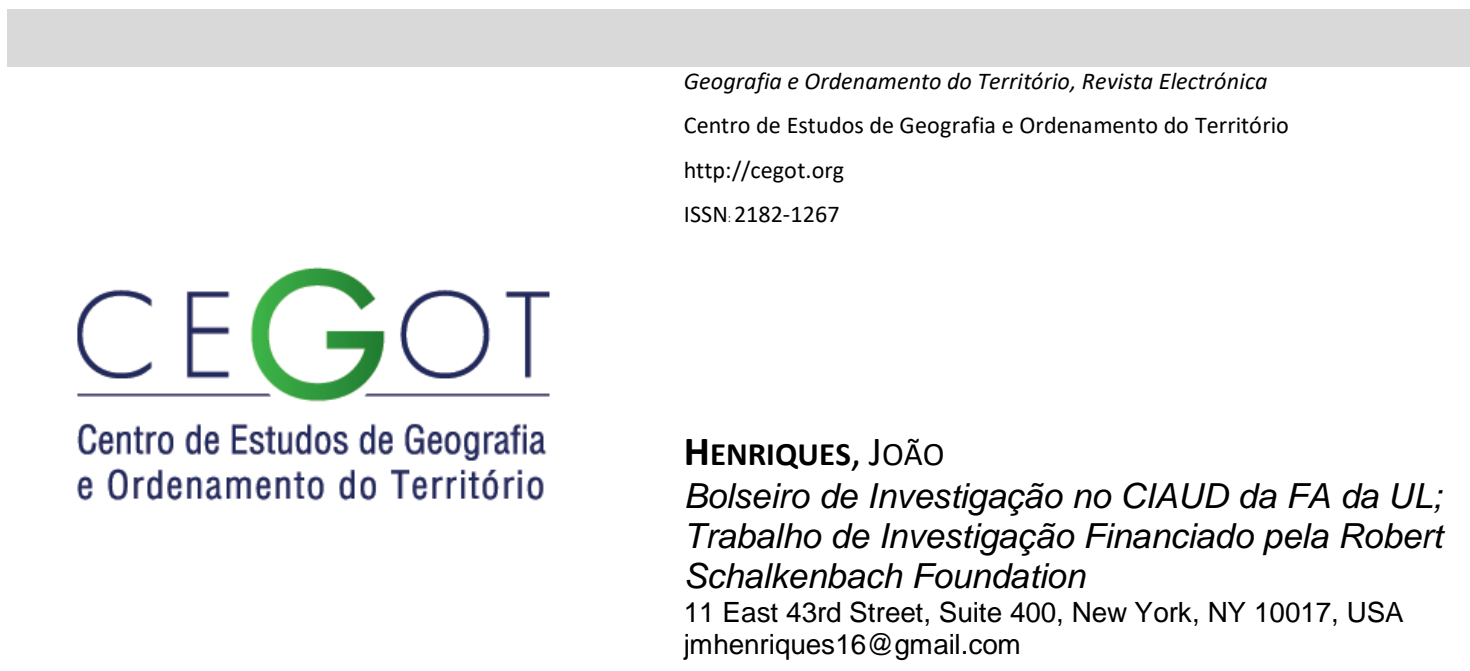

\title{
A bolha imobiliária de 2008: uma análise acerca da evolução do valor dos imóveis em Portugal
}

The Real Estate Bubble of 2008: an analysis regarding the evolution of real estate values in Portugal

Referência: Henriques, João (2017). A bolha imobiliária de 2008: uma análise acerca da evolução do valor dos imóveis em Portugal. Revista de Geografia e Ordenamento do Território (GOT), n. 11 (junho). Centro de Estudos de Geografia e Ordenamento do Território, p. 215-239, dx.doi.org/10.17127/got/2017.11.010

\section{RESUMO}

Em Portugal, em termos políticos, evitou-se reconhecer que a origem do colapso económico de 2008 se deveu às dinâmicas internas do mercado imobiliário. Este artigo procura verificar se existiu negligência na análise dos sucessivos Governos, por removerem esta hipótese como causa direta da crise ou se a mensagem tinha um fundamento técnico-científico que validasse a rejeição da hipótese que defende que a crise foi originada pela bolha imobiliária. Neste sentido, opta-se pela aplicação parcial do "Modelo dos Ativos Reais" desenvolvido por Gaffney (2015), onde se testa a hipótese relacionada com a evolução dos valores do solo. Uma das inovações introduzidas é a espacialização do próprio modelo, através da desagregação da análise até à escala do Município de Lisboa.

Palavras-chave: bolhas imobiliárias, Portugal, uso do solo, economia.

\section{ABSTRACT}

In Portugal, the political structures avoided to acknowledge that the source of 2008's economic collapse was due to the internal dynamics of real estate market. This article seeks to verify if there was negligence on the analysis of the successive Governments, for withdraw this hypothesis as a direct cause of the crisis, or if the message had scientific- 
technical foundations that could validate the rejection of the hypothesis, which advocates that the crisis was originated by the real estate bubble.

Then, it is chosen the partial application of the "Real Assets Model" developed by Gaffney (2015), where it is tested the hypothesis related with the evolution of land values. One of the introduced innovations is the spatial application of the own model, through the disaggregation of analysis until the Lisbon's Municipality scale.

Keywords: Real estate bubbles, Portugal, Land-use, Economics.

\section{Enquadramento}

A origem da crise económico-financeira tem sido justificada, politicamente, como sendo resultado da crise internacional. Portanto, defende-se que a crise portuguesa implodiu devido à crise interna dos EUA (a crise do "sub-prime"), com o argumento de que esta se propagou pelo Mundo Ocidental. Esta explicação permitiu desviar as atenções acerca dos problemas produzidos pelas dinâmicas do mercado interno. Face a este contexto, o artigo pretende testar a hipótese de que a crise económica é explicada por fatores internos.

Em função da realidade observável, nomeadamente, através do conhecimento acerca dos processos de transformação que marcaram a evolução recente dos centros urbanos em Portugal, é possível extrapolar que as dinâmicas do mercado imobiliário têm de conseguir explicar, para uma maior ou menor extensão, a crise económico-financeira de 2008. Deste modo, a hipótese proposta anteriormente pode ser detalhada: a crise económica financeira deriva da existência de uma bolha no mercado imobiliário.

Para explorar esta tese, é aplicado o Modelo dos "Ativos-Reais" desenvolvido por Gaffney (2015), que de acordo com o Autor, pode ser testado através de quatro hipóteses, sendo que esta investigação aborda a primeira delas, nomeadamente: "(i) uma subida e queda dos valores do solo, resultantes de alterações na economia real. Estas são menos visíveis $e$ medidas do que as alterações puramente monetárias e fiscais, que podem reforçar $e$ refletir as alterações na economia real, mas não as iniciam (Gaffney, 2015: 327).

Este artigo integra uma parte de um projeto de investigação estruturado em torno do seguinte objectivo: demonstrar que a bolha imobiliária foi o principal epicentro da crise económica em Portugal através das quatro hipóteses propostas pelo Modelo dos "AtivosReais". Neste sentido, é aqui desenvolvida a primeira hipótese proposta pelo modelo económico numa abordagem centrada na análise ao valor dos imóveis transacionados ao longo de um período de 15 anos (2000-2014). 


\section{A Bolha Imobiliária de 2008}

A crise económico-financeira de 2008 tem sido explicada com base em diferentes tipos de causas. Entre estas, está a bolha imobiliária, onde se argumenta que o ciclo marcado por uma subida vertiginosa dos preços do imobiliário num curto espaço de tempo, seguido de um colapso repentino, acabou por criar uma paralisação do sistema económico em diversas nações ocidentais.

O Estado da Arte relacionado com a bolha imobiliária de 2008 tem vindo a desenvolver abordagens específicas e gerais. As específicas enquadram o tema da bolha imobiliária numa perspetiva temática (regra geral centradas sobre um tema: taxas de juro; habitação, etc.) e considerando, normalmente, apenas uma escala territorial (Ex: Espanha, Estados Unidos da América, Irlanda, Portugal, etc.). As abordagens gerais consideram uma maior diversidade de temas, distribuindo a análise do fenómeno pelos diversos fatores, que para uma maior ou menor extensão, possam ser explicativos do mesmo, sendo geralmente aplicadas a mais do que uma escala territorial. Este artigo está enquadrado no primeiro tipo de abordagem.

As abordagens específicas têm analisado pelo menos um fator explicativo da formação da bolha imobiliária (não quer dizer que não abordem outros também, mas o foco está normalmente colocado num ou no máximo em dois destes fatores). Deste modo, existem estudos que evidenciam a formação da bolha a partir da evolução do valor das casas (Lopez García, 2004; Fundación Alternativas, 2007; Aalberts, 2009; Arellano e Bentolila, 2009; Hoekstra e Vakili-Zad, 2011; Rodríguez López, 2012; Sumner, 2015); na quantidade de alojamentos vagos, registados após o rebentamento da bolha, geralmente relacionando este indicador com o número de famílias (Bingre do Amaral, 2011; Hoekstra e Vakili-Zad, 2011); no ritmo de construção e urbanização (Arellano e Bentolila, 2009; Rodríguez López, 2012), associando este processo com os respetivos impactos na distribuição e configuração espacial dos assentamentos urbanos e no equilíbrio ecológico dos sistemas territoriais (Fundación Alternativas, 2007; Etxezarreta Etxarri et al., 2012; Delgado Viñas, 2012; Romero et al., 2012); na evolução do endividamento e no crescimento explosivo das execuções hipotecárias, após o colapso da bolha (Aalberts, 2009; Bingre do Amaral, 2011; Etxezarreta Etxarri et al., 2012).

Nas abordagens gerais sobre a bolha imobiliária são desenvolvidos raciocínios, empiricamente fundamentados, que explicam determinada evolução dos preços do solo (ou do imobiliário em geral) dentro de um determinado período (em conjunto, esta problemática é designada por ciclo imobiliário), destacando quer as causas quer as consequências da referida evolução. Dentro deste modelo científico existe um trabalho 
clássico, onde se analisam, detalhadamente, cinco ciclos imobiliários à escala da metrópole/cidade/povoamento de Chicago, que constitui, ainda hoje, uma referência para o entendimento da problemática (Hoyt, 1933) e mais recentemente, Foldvary (2007), Harrison (2010 [2005]), Gaffney (2009; 2015) e Henriques (2015) acrescentam novo conhecimento, centrado sobre a formação e a evolução da última bolha imobiliária, em diferentes escalas e contextos territoriais.

\section{A subida e a queda dos preços do solo}

Uma bolha consiste na sobrevalorização de um determinado ativo durante um curto espaço de tempo (Foldvary, 2004; Henriques, 2015). Neste sentido, o objetivo é perceber se o imobiliário, enquanto ativo, se enquadra neste tipo de definição. Em função dos dados existentes e da informação que se pretende obter, esta abordagem deve contemplar no mínimo dois níveis de análise: (i) a escala agregada (âmbito nacional) e (ii) a escala desagregada (âmbito regional e urbano). A primeira reflete o peso do fenómeno (a bolha imobiliária) à escala nacional. Se existir uma crise económica que afeta o País como um todo, então a causa que está na origem dessa mesma crise pode ser explicada/observada em todas as regiões e cidades, ainda que possam existir diferenças de amplitude entre estas (Romero et al., 2012; Glaeser, 2013). Na segunda abordagem, processa-se uma análise aprofundada do problema. Se a bolha imobiliária for comprovada, então podem ser identificados os tipos de propriedade que estão sobrevalorizados e as características dos territórios onde predominam este tipo de propriedades (ou seja, onde é que estas propriedades estão localizadas).

Em Portugal, uma observação atenta acerca da morfologia e das características da ocupação do solo nas áreas urbanas em Portugal, em particular, nas vilas e nas cidades (ou noutros povoamentos diretamente dependentes destes territórios) evidencia problemas similares, que só variam em função da escala das diferentes realidades. Naturalmente, este trabalho não irá explorar todos estes espaços com o detalhe exigido, pois um trabalho desta natureza requer um foco. Neste sentido, o foco é a Área Metropolitana de Lisboa e neste capítulo em particular, o maior nível de desagregação de informação (escala municipal) está centrado apenas em Lisboa (Ver subcapítulo 3.3). 


\subsection{A Escala Nacional}

Infelizmente, não existem dados que permitam aferir com precisão o valor do solo, visto que os montantes determinados para transacionar ou avaliar os imóveis não diferenciam o valor do capital do valor do solo. Em função destas limitações, é utilizado o valor total dos imóveis como referência para esta análise.

A Figura 1 contempla a informação referente aos registos dos valores médios de todas as transações de imóveis realizadas em Portugal entre 2000 e 2014 e confirma que os valores dos imóveis transacionados atingiram um pico em 2007: (i) entre 2000 e 2007, os valores dos imóveis duplicaram (subida de 97\%), aumentando 10,20\%, em média por ano; (ii) embora o pico tenha sido atingido em 2007, o valor médio dos imóveis mantém-se elevado em 2008, ano em que rebenta a bolha imobiliária. Entre 2008 e 2009, os preços caiem 11\% e se for considerado o intervalo entre 2008 e 2012, a queda dos preços chega aos 34\%.

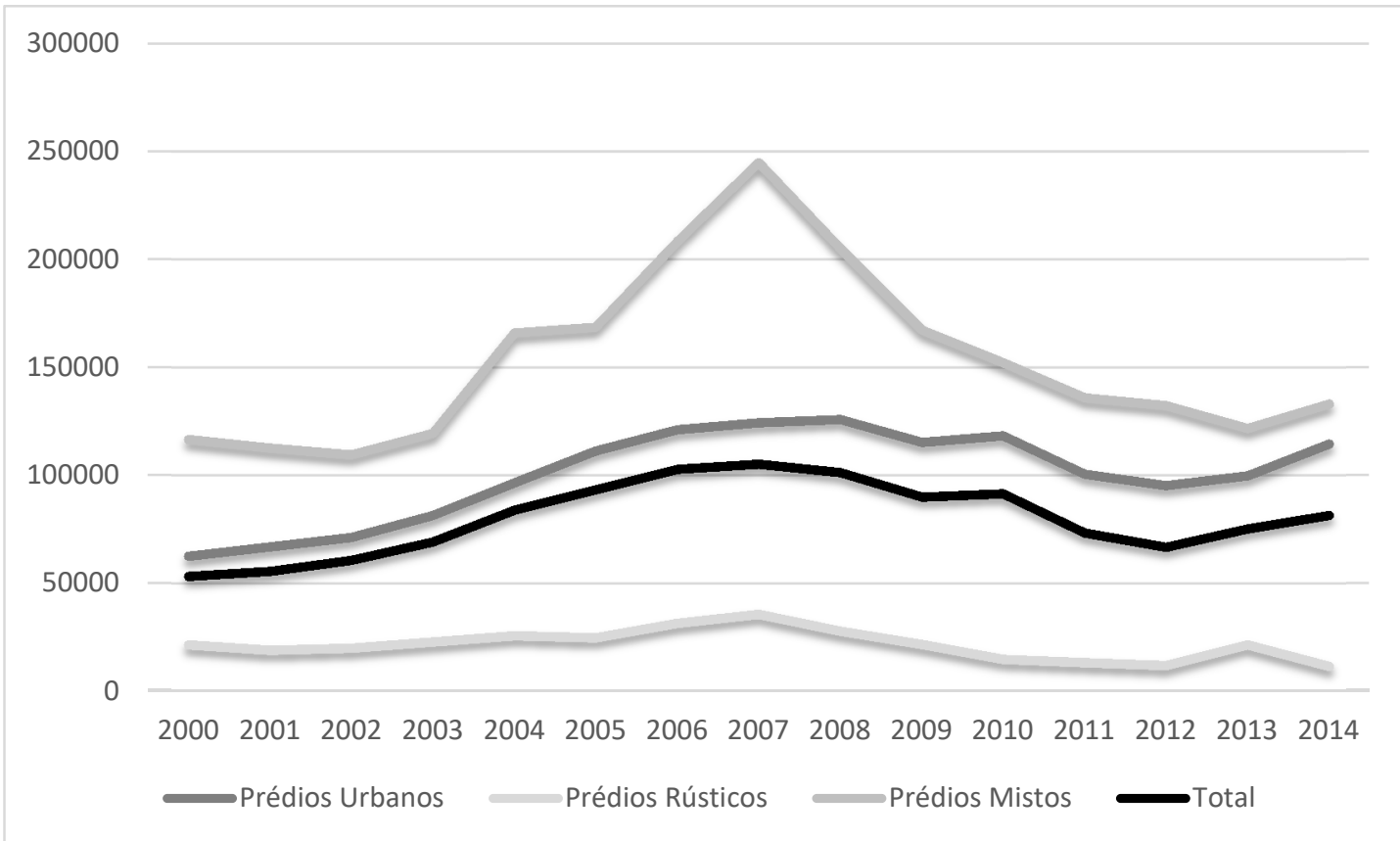

Figura 1 - Valor Médio (€) dos Contratos de Compra e Venda de Imobiliário em Portugal (2000-2014) Fonte: Adaptado de INE (2015a).

De forma complementar, o INE (2015b) fornece também informação relativa ao número de transações de imóveis para o mesmo período temporal, que ajudam a explicar o fenómeno da bolha imobiliária: (i) entre 2000 e 2007, o ano com o menor número de propriedades transacionadas é 2007. Aparentemente, este é um dado contraditório com a informação referente ao valor médio das propriedades: o número de contratos de compra e venda de imóveis caiu 18,72\% (ou seja, em 2007 foram assinados menos 64.823 contratos do que em 2000). (ii) Considerando o período entre 2000 e 2007 como a fase de expansão, e o período 
entre 2008 e 2014 como a fase de depressão do ciclo imobiliário e calculando, posteriormente, a média do número de transações para ambas as fases (298.506 e 179.837 contratos por ano, respetivamente), permite constatar que o número médio anual de transações de imóveis é superior em cerca de 120.000 contratos na fase de expansão, por oposição ao valor registado na fase de depressão.

Os números demonstram que a bolha imobiliária existiu e, portanto, esta não pode continuar a ser um elemento negligenciado quando se analisam as causas da crise económico-financeira de 2008.

Em todo o caso, e apesar de se ter alcançado um dos objetivos deste trabalho, a informação disponível permite aprofundar o conhecimento acerca do fenómeno. A informação da Figura 1 demonstra que os valores médios das propriedades de uso misto são superiores aos valores médios dos imóveis urbanos, que por sua vez, são superiores aos dos prédios rústicos. Relativamente ao número de transações de imóveis, verifica-se que os prédios urbanos são o tipo de propriedade com maior representatividade na dinâmica do mercado imobiliário (entre 2000 e 2014, os imóveis urbanos representam, em média, 72,64\% do fluxo total de imóveis transacionados), seguidos dos prédios rústicos e por último, dos prédios mistos (INE, 2015b). Estes dados aparentam ser pouco relevantes para os objetivos deste trabalho, contudo esta sensação é ilusória, pois esta é a informação que melhor permite compreender a formação/origem do problema (bolha imobiliária), visto que estabelece a ponte entre a análise numérica e a análise espacial: (i) as propriedades de uso misto correspondem a imóveis que têm uma parcela (ou conjunto de parcelas) de solo urbano (cuja utilização principal não está diretamente ligada à atividade agrícola ou florestal) e uma parcela (ou conjunto de parcelas) de solo rural dentro dos seus limites cadastrais (Autoridade Tributária e Aduaneira, 2013). A definição é generalista, mas esta cobre propriedades como Quintas (particularmente aquelas que estão situadas nas áreas adjacentes ou mesmo no interior dos limites das cidades). Esta é a explicação para o reduzido número de transações e para o elevado valor médio dos imóveis; (ii) as propriedades urbanas incluem diferentes tipos de imóveis localizados quer em povoamentos urbanos quer em paisagens rurais. Se for de uso residencial dentro da cidade, a propriedade pode ser um apartamento, uma moradia ou um lote vago. Se for utilizado para comércio (ou se estiver disponível para vir a ser utilizado para esse fim) pode ser uma loja, um centro comercial ou um lote vago. E assim sucessivamente; (iii) as propriedades rurais incluem as maiores discrepâncias entre os vários tipos de propriedade, embora possam passar despercebidas. Existem desde parcelas com plantações agrícolas ou florestais, até parcelas agrícolas sem qualquer utilização e ainda parcelas de solo urbano vazio. Esta situação pode gerar confusões, mas as parcelas localizadas dentro dos limites da cidade, que permanecem em estado bruto, podem ser classificadas como propriedades 
rurais para propósitos fiscais (Autoridade Tribuária e Aduaneira, 2013). Outro exemplo idêntico são as propriedades rurais (mesmo sem qualquer plantação) classificadas como solo urbano ou disponíveis para urbanização e edificação nos modelos de ordenamento do território. Ao identificar e perceber este tipo de situações, compreende-se a evolução recente da cidade e a justificação para o valor de mercado dos diferentes tipos de propriedades. Para explorar melhor esta questão, a informação deve ser desagregada.

\subsection{A Escala Regional}

Nesta fase, tem que ser selecionada a região que melhor explique a flutuação dos preços do solo assim como a dimensão espacial do fenómeno. Para recolher a maior quantidade de elementos explicativos da bolha imobiliária, um critério a adotar, deve ser a opção por uma região com cidades, de preferência de grande dimensão, onde a sua preponderância face ao total de riqueza produzida e ao total de habitantes possa ser facilmente observável. Em função deste critério e tendo como base a bibliografia de referência (Hoyt, 1933), a opção é aplicar o modelo centrado sobre a Área Metropolitana de Lisboa (AML).

Esta região constitui a maior aglomeração urbana do País: em 2014, residiam ao todo, 2.809.168 habitantes, dos quais, 509.312 moravam em Lisboa (INE, 2015c). Embora existam 18 Municípios, a AML tem apenas 17 cidades. Deste modo, há Municípios com mais do que uma cidade e Municípios sem qualquer cidade (INE, 2001; 2016). Destas 17 cidades, apenas duas têm mais de 100 anos: Lisboa e Setúbal (INE, 2001). Até 1990, existiam apenas 7 cidades nesta região metropolitana. As outras 10 cidades adquiriram o seu estatuto oficial durante o último ciclo imobiliário.

A cidade de Lisboa está localizada na margem direita (norte) do Estuário do Tejo. A cidade de Setúbal está localizada na margem direita do Estuário do Sado (situado a sul do Estuário do Tejo). Desde a inauguração da Ponte 25 de Abril (1966), as duas cidades começaram a estar a separadas por $50 \mathrm{~km}$, inicialmente por estrada e mais tarde também por ferrovia. 0 grande crescimento urbano registado nos Municípios que estavam situados ao longo desta rota é principalmente explicado pela proximidade à Capital. Os efeitos da escassez artificial do mercado de solos são regionais no caso da cidade de Lisboa e apenas locais no caso da cidade de Setúbal. Deste modo enquanto a cidade de Lisboa explica o crescimento dos 16 aglomerados que se tornaram cidade ao longo dos últimos 50 anos, Setúbal não consegue explicar o desenvolvimento de qualquer aglomerado que se tenha tornado cidade. Este raciocínio pode ser comprovado através de observação direta: por exemplo, comparando os limites de Setúbal enquanto cidade com os limites administrativos do respetivo Município. Para aplicar este método, pode ser utilizada uma ferramenta simples como o Google Earth, através do qual se demonstra (utilizando imagens de satélite) que os atuais limites da cidade 
não chegam a alcançar os limites do Município - em alternativa, os números também demonstram esta evidência, uma vez que a área ocupada pelo perímetro urbano da cidade de Setúbal representa apenas $16 \%$ da superfície da Jurisdição do Município de Setúbal (INE, 2015d; 2015f). Mesmo com dinâmicas de desenvolvimento urbano centradas sobre as áreas periféricas, Setúbal, por si só, não consegue explicar o desenvolvimento/surgimento de nenhuma nova cidade. No máximo, esta cidade consegue apenas explicar a formação de pequenos povoamentos dispersos ou subúrbios nos Municípios vizinhos, em particular, em Palmela, que por sua vez, não tem qualquer cidade e é sobretudo caracterizado por vastas áreas de solo rural apenas quebradas, na sua maioria, por povoamentos dispersos (que podem até ocupar uma extensão de solo significativa, mas onde mora um pequeno número de pessoas) (INE, 2016).

O exemplo da influência da cidade de Setúbal é comparável com o verificado noutras cidades portuguesas, como Leiria e Coimbra. Estas cidades ainda não alcançaram os limites administrativos (e estão longe do conseguirem fazer), logo os efeitos da escassez artificial são apenas visíveis a uma escala local - A superfície delimitada pelo perímetro urbano da cidade de Coimbra corresponde a pouco mais de $1 / 4$ do Território Municipal (26,05\%) e a da cidade de Leiria chega apenas aos $7 \%$ da área abrangida pela Jurisdição Municipal (INE, 2015d; 2015f). Esta escala local corresponde à cidade e à sua área envolvente ou incluí outros povoamentos que estão próximos da cidade através de rotas rápidas (mesmo que localizados noutras jurisdições). Em termos estatísticos, as cidades, que não estão incluídas numa Área Metropolitana, são irrelevantes. As unidades territoriais, onde a informação está disponível, são demasiado extensas para explicar a realidade à escala da cidade.

Através deste raciocínio é demonstrado que os limites administrativos dos Municípios raramente coincidem com os limites das cidades, mesmo numa Área Metropolitana. Ao mesmo tempo, funciona como um argumento a favor da opção de desagregação da informação existente à escala nacional e regional, de forma a expandir o conhecimento acerca da formação do valor do imobiliário.

Deste modo, os valores monetários das propriedades rurais transacionadas, que refletem uma elevada proporção do valor do solo (devido a pressões urbanas) sobre o valor global dos imóveis, só podem ser explicados num pequeno número de Municípios. Nomeadamente em municípios como Lisboa, Almada, Barreiro, Amadora, Odivelas, Cascais e Oeiras. E mesmo nesta lista, existem municípios que não têm cidades como Cascais e Oeiras (INE, 2016). Apesar disso, estes são dois municípios densamente povoados (a esta escala) - Em 2014, Cascais tinha 209.376 habitantes e Oeiras tinha 172.959 habitantes; A nível regional, Cascais é o 60 município com maior densidade populacional (2.150 indivíduos 
por $\mathrm{km}^{2}$ ) e Oeiras posiciona-se no 4 o lugar neste mesmo indicador (3.770 indivíduos por $\mathrm{km}^{2}$ ) (INE, 2015c; 2015d; 2015e).

Em todo o caso, mesmo não sendo identificados como cidades, estes constituem, pelas suas características territoriais, grandes extensões de Lisboa. No município de Cascais existem aglomerados urbanos com dimensão significativa como os povoamentos de Cascais-Estoril, da Parede e de Alcoitão-Alcabideche, enquanto no município de Oeiras surgem os povoamentos de Oeiras-Caxias, Algés, Porto Salvo, Carnaxide, Queijas. Como um todo, estes povoamentos ocupam a maioria do território dos respetivos municípios, sendo esta uma explicação para o valor do solo ter um peso tão significativo no valor de mercado das propriedades rurais.

Esta observação pode ser complementada com outros elementos. Por exemplo, se o objetivo for obter o total de população a residir em áreas densamente povoadas (cidades e vilas), verifica-se que a informação disponível (INE, 2015c; 2015d; 2015e) tem muitas imperfeições: não existe informação para o número concreto de residentes em cada um dos principais povoamentos dos municípios de Cascais e Oeiras ou para o número de residentes em Mem-Martins (Sintra). Deste modo, segundo a informação publicada pelo INE (2015f; $2015 \mathrm{~g}$ ), em 2011, 51,71\% (1.459.272 indivíduos) da população que residia na AML morava numa das suas 17 cidades. Confrontando este número com a observação anterior, pode-se extrapolar que o número de pessoas a residir em áreas urbanas densamente povoadas será consideravelmente superior aos números apresentados.

Apesar de tudo, não deixa de ser relevante assinalar que os dados publicados pelo INE (2015f; 2015g) confirmam que mais de metade da população residente na AML está concentrada numa área (englobando todas as cidades) que equivale a apenas $9 \%$ da superfície desta região.

Neste sentido e mesmo considerando os defeitos da informação existente, a conclusão é que a $A M L$ não é uma região urbana densamente ocupada, quando comparada com outras metrópoles a uma escala mundial. Porque só uma fração minoritária do seu território é que está ocupada por cidades. Por exemplo, o segundo município da AML (e até à escala nacional) com maior número de residentes é Sintra, que tem duas cidades e ambas possuem uma densidade populacional superior à da cidade de Lisboa (INE 2015f, 2015g). Porém a densidade populacional do município de Sintra é muito baixa (1.193 indivíduos por $\mathrm{km}^{2}$ ) quando comparada com os dados existentes quer para as duas cidades quer para o número total de habitantes (em 2011, residiam nas duas cidades (Agualva-Cacém e QueluzMassamá) 44,49\% (ou 168.094 indivíduos) do total de habitantes do Município de Sintra (377.835)) (INE, 2015c; 2015f; 2015g). 
Estas diferenças extremas de densidades dentro de um pequeno território explicam-se pela presença de cidades e povoamentos densamente povoados integrados num município que, em simultâneo engloba ainda vastas áreas, nas quais o uso do solo predominante não é o uso urbano: o Parque Natural da Serra de Sintra (que se estende até ao município de Cascais) e uma área com características rurais proliferada por pequenos povoamentos (em regra, com uma morfologia urbana enquadrada nos modelos de ocupação dispersa). As duas cidades foram implantadas nas imediações da principal rota para Lisboa (a Linha de Sintra e - Itinerário Complementar 19) e juntas ocupam uma pequena fração da superfície do Município (5,36\% ou 17,1 km²) (INE, 2015f; 2015g). Se outros povoamentos com características marcadamente idênticas às das duas cidades (como Mem-Martins) forem adicionados a estes cálculos, provavelmente a superfície ocupada por povoamentos densamente urbanos continuará a ser minoritária (inferior a $20 \%$ da área do Município). Os números são propositadamente conservadores porque os limites reais das áreas predominantemente urbanas e densamente ocupadas podem ser superiores aos limites administrativos nos quais se baseia a informação recolhida pelo INE (Brenner e Schmid, 2015).

Este raciocínio demonstra que o segundo município com maior número de habitantes (em Portugal) tem apenas entre 10 a $20 \%$ do seu território ocupado por áreas predominantemente urbanas. Logo, a grande dimensão das áreas administrativas (municípios) para as quais tem sido recolhida a informação não é compatível com a dimensão das cidades existentes em cada um dos municípios (com pequenas exceções). A prova disso mesmo é que estes factos podem ser confirmados até numa escala metropolitana: "o Google Earth e as imagens de satélite podem demonstrar, mesmo a um observador comum, que o desenvolvimento urbano é apenas uma pequena fração da área total" (Fischel, 2012: 273). Neste sentido, os valores das transações de imóveis analisados a uma escala municipal nem sempre mostram o impacto real da especulação imobiliária no valor final da compra e venda.

O impacto da especulação imobiliária (próximo do real) no valor final dos imóveis transacionados pode ser evidenciado quando se verificam dois pressupostos: (i) na escala regional, quando a dimensão urbana (uma rede constituída por várias cidades com dimensão significativa) assume um peso determinante e, portanto, uma elevada representatividade no dinamismo social e económico do território onde se insere. Por outras palavras, as transferências de imóveis (números e valores das transações) em áreas afetadas por pressões urbanas dominam as dinâmicas do mercado imobiliário regional; (ii) e na escala municipal/local, quando a cidade (em conjunto com outros povoamentos urbanos diretamente ligados ao desenvolvimento de uma cidade) tem uma dimensão assinalável dentro da jurisdição em que está integrada. O município tem que se confundir com a cidade, 
isto é, as características do território administrativo têm que ser, na maioria da sua extensão, muito próximas das características de uma cidade. O território não pode apresentar uma grande heterogeneidade paisagística. Pelo menos não nos casos em que se observa uma dicotomia entre grandes extensões contínuas de solo com características marcadamente rurais com pequenas extensões predominantemente urbanas (onde estão integradas as cidades), como se verifica no caso de Sintra, por exemplo.

A Figura 2 contempla o valor médio dos imóveis transacionados dentro dos limites administrativos da Área Metropolitana de Lisboa. Os dados validam a hipótese de que a bolha imobiliária colapsou em 2008: entre 2000 e 2008, o valor médio dos imóveis transacionados aumentou 96,70\% (quase que duplica o valor médio inicial) e por ano, a subida é equivalente a 8,82\%. De 2008 a 2012 ou durante a fase recessiva do ciclo imobiliário, o valor médio das propriedades transacionadas caiu $17,50 \%$ ou $4,70 \%$ ao ano.

Por tipo de propriedades, os imóveis rurais e urbanos atingiram o pico no mesmo ano: 2008, e as propriedades de uso misto alcançaram o pico em 2006, contudo mantiveram-se com valores elevados até 2010. O valor das propriedades urbanas aumentou 8,69\%, por ano entre 2000 e 2008, ou 94,76\% considerando apenas as alterações entre os valores registados nestes dois anos. O valor das propriedades rurais subiu $168,56 \%$ durante 0 mesmo período, ou 13,14\% por ano. Considerando o mesmo período para os imóveis de uso misto, a subida foi de $78,18 \%$ ou $7,49 \%$ ao ano. Após o pico de 2008 , o mercado entra em recessão: as propriedades urbanas chegam ao fundo em 2011 assim como o valor médio do total de propriedades transacionadas, contudo os valores de 2012 também podem explicar a queda dos valores do imobiliário (os valores dos imóveis são semelhantes para todos os tipos de propriedade, entre estes dois anos). Consequentemente, o valor médio dos imóveis urbanos caiu 4,06\% ao ano entre 2008 e 2012, ou 15,26\% no total. Os valores médios de transação de propriedades rurais caíram a um ritmo de $18,76 \%$ por ano ou $56,50 \%$ entre os dois anos (perderam mais de metade do valor). Uma tendência similar verifica-se nos prédios de uso misto, cujo valor caiu $54,25 \%$ neste período ou $17,76 \%$ ao ano.

Neste sentido, a abordagem regional reforça as evidências obtidas a uma escala agregada. A Figura 2 representa a informação acerca de uma região metropolitana, pois a bolha imobiliária deve ser evidenciada à escala urbana (Hoyt, 1933). Porém, também tem sido demonstrado que o solo urbano, em particular o solo ocupado por cidades, mesmo numa área metropolitana corresponde apenas a uma pequena fração do total de solo disponível. Além dos factos apresentados, da comparação entre os dados disponíveis para a escala nacional e para a escala regional consegue-se extrair informação relevante para a investigação: (i) o valor médio das propriedades urbanas, transacionadas entre 2000 e 2014, localizadas na Área Metropolitana de Lisboa corresponde a $162,75 \%$ do valor médio do 
mesmo tipo de imóveis à escala nacional; (ii) o valor médio dos imóveis rurais transacionados, durante o mesmo período e localizados na Área Metropolitana de Lisboa, corresponde a 957,37\% do valor médio do mesmo tipo de propriedades à escala nacional; (iii) o valor médio das propriedades mistas, durante o mesmo período, equivale a 486,57\% do valor médio do mesmo tipo de propriedades transacionadas à escala nacional. Considerando todas as transações de imóveis, as propriedades transacionadas à escala regional (metropolitana) têm, em média, o dobro (207,16\%) do valor das propriedades transacionadas à escala agregada.

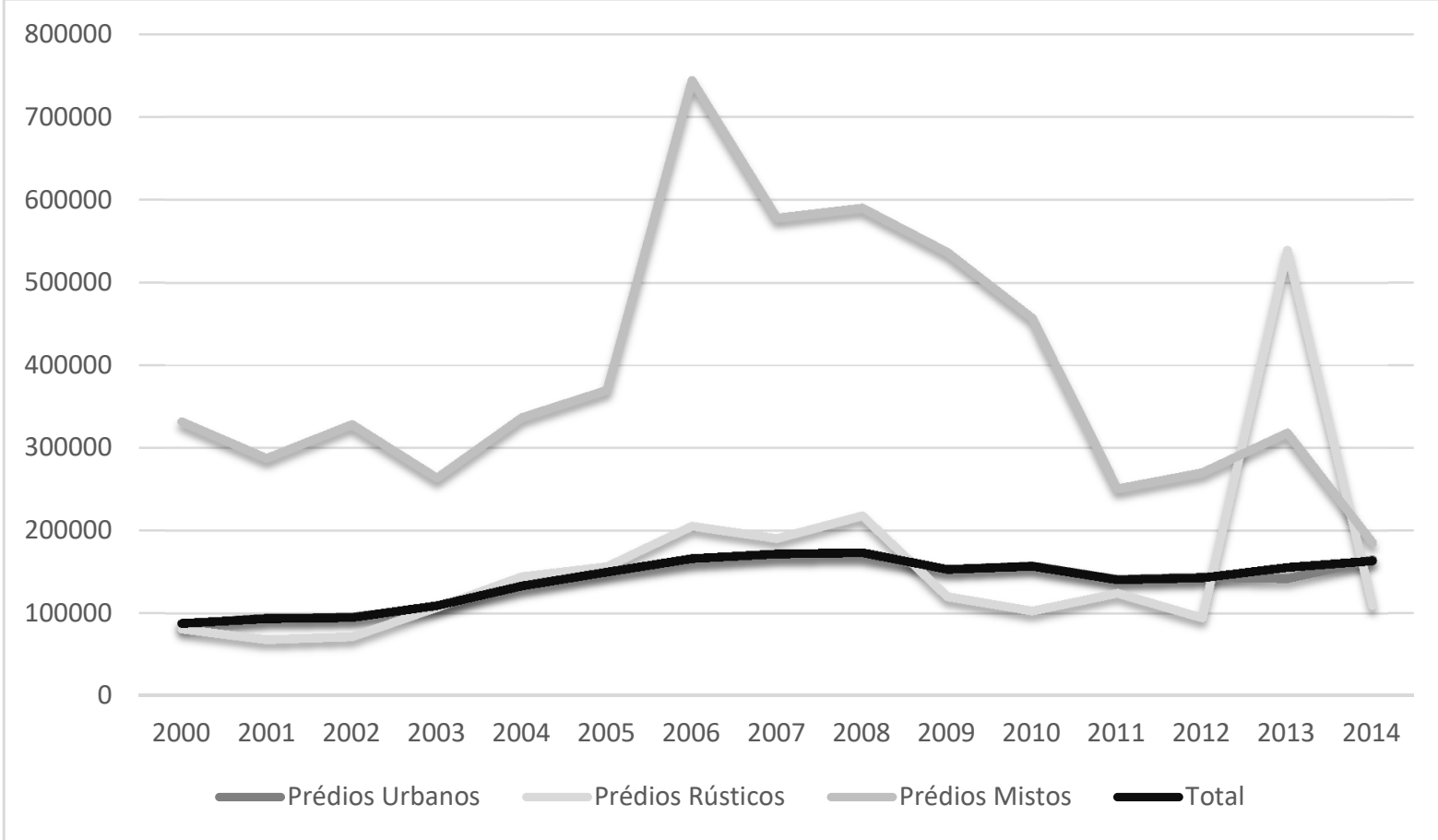

Figura 2 - Valor Médio $(€)$ dos Contratos de Compra e Venda de Imóveis localizados na Área Metropolitana de Lisboa (2000-2014)

Fonte: Adaptado de INE (2015a)

O destaque desta análise consiste na diferença de valores verificada entre as propriedades rurais e as propriedades de uso misto na escala regional e na escala nacional. Estes valores refletem o valor global do imobiliário, logo não distinguem o valor do solo do valor do capital. Porém, se os valores do solo têm um peso significativo nos preços do imobiliário à escala nacional (conforme foi demonstrado), então é evidente que na Área Metropolitana de Lisboa, os valores do solo estão de longe mais inflacionados. Assim se valida a teoria de Henry George: "As vantagens que este solo [das cidades] oferece à aplicação do trabalho são de tal forma enormes, que em vez de um Homem acompanhado por um conjunto de cavalos a desbravar acres - equivale a aproximadamente 0,4 hectares - é possível encontrar lugares com milhares de trabalhadores, trabalhando lado a lado, em pisos que crescem sobrepostos uns aos outros, cinco, seis, sete e até oito pisos a partir da superfície, enquanto 
por debaixo da terra existem motores que replicam, através de pulsações, a força de mil cavalos. Todas estas vantagens são absorvidas pelo solo; é neste solo e não noutro, que estas podem ser utilizadas, porque aqui é o centro da população - o foco das trocas, o lugar de mercado e o lugar de trabalho das formas mais avançadas da indústria. Os poderes produtivos que a densidade populacional tem anexado a este solo são equivalentes à multiplicação da sua fertilidade natural por 100 ou 1000. E a renda que mede a diferença entre esta produtividade adicionada e aquela do solo menos produtivo em utilização tem crescido em conformidade" (George, 2009 [1881]: 217); "George viu as cidades como centros de comunicação, cooperação, socialização [convívio] e trocas comerciais, que ele considera serem as bases da Civilização. Ele viu as cidades como a nova fronteira, uma série sem fim de novas descobertas, porque a cidade como um todo beneficia de retornos crescentes. A presença das pessoas com fácil acesso mútuo em termos equivalentes agiliza a cooperação e a especialização através do mercado. Interações multivariadas nas cidades são sinérgicas. De facto, enquanto cada parte - cada parcela de solo - é desenvolvida numa base de retornos decrescentes, a cidade consolidada está geralmente numa fase de retornos crescentes, graças às sinergias. Como um todo é maior do que a soma das suas diferentes partes; as valorizações do solo geram mais retorno do que a soma das valorizações de cada uma das diferentes partes" (Gaffney, 2001: 63). As referências utilizadas são uma demonstração do reconhecimento da força económica e social das cidades.

Este reconhecimento é natural, visto que as cidades são o motor do progresso material, e o nível de progresso pode ser medido pelos valores do solo (que por sua vez representa a diferença de produtividade das cidades em comparação com o solo em utilização noutras áreas territoriais distintas). É nas cidades que o valor do solo é mais elevado, porque é aí que as pessoas conseguem alcançar mais e melhores oportunidades para empregar o seu trabalho e investir o seu capital. À escala nacional, Lisboa e a Região da Área Metropolitana de Lisboa correspondem à maior massa humana de Portugal e isto explica a diferença evidente entre o valor médio das propriedades transacionadas à escala regional e à escala agregada. A diferença é medida pelos valores do solo ou pelas rendas que podem ser obtidas dentro de uma determinada área em comparação com o que pode ser obtido fora dessa mesma área. Isto não determina que o solo dentro e em redor de outras cidades situadas fora das Áreas Metropolitanas (Lisboa e Porto) não alcance também um valor especulativo. Verifica-se exatamente o mesmo processo (embora a intensidade possa ser menor, dependendo da dimensão de cada cidade), porque também nestas cidades "para adquirir a propriedade do solo, as pessoas pagam preços que parecem muito elevados relativamente aos fluxos de caixa correntes" (Gaffney, 2001: 64). Contudo, em Portugal estes locais têm dificuldades para ser estatisticamente relevantes mesmo à escala local (Município), porque a área coberta pela cidade (e a sua área envolvente) não chega a 
alcançar, na maioria dos casos, se quer metade da área administrativa (para onde é recolhida a maioria da informação) onde estão localizadas. Esta questão insere-se no raciocínio desenvolvido anteriormente para justificar a desagregação dos elementos estatísticos referentes ao valor médio dos imóveis transacionados e a opção pela condução desta investigação centrada sobre a cidade de Lisboa.

O autor (Henriques, 2015) evidenciou o fenómeno da sobrevalorização do solo numa pequena cidade (A cidade do Entroncamento, que em 2011 contava com pouco mais de 20.000 habitantes) localizada fora da área administrativa das duas Áreas Metropolitanas, onde foi possível confirmar o peso estatístico dos valores do solo à escala local (Município), porque a cidade e as suas áreas envolventes já excederam os limites do Município (o Município do Entroncamento é, em área, o segundo Município mais pequeno do País), logo a informação coletada à escala municipal pode ser utilizada para explicar as flutuações anuais do valor do solo à escala da cidade.

Embora a bolha imobiliária seja também evidente à escala metropolitana, se a análise estiver centrada apenas nos dados da Figura 2, podem ser geradas algumas confusões: por exemplo, a média dos valores médios das propriedades transacionadas, considerando os dois períodos do ciclo imobiliário (2000-2008 e 2008-2012), mostra valores médios das transações de imóveis superiores na fase recessiva em comparação com o verificado na fase de expansão (INE, 2015b). Nesta abordagem, a diferença dos valores médios de todos os tipos de imóveis transacionados entre a fase recessiva e a fase de expansão é de $17.341,88 €$. Isto poderia ser utilizado para desvalorizar uma parte das conclusões deste artigo; contudo, a informação onde consta o número de propriedades transacionadas nesta escala (INE, 2015b) ajuda a esclarecer este ponto.

Antes de avançar para esse esclarecimento, merece destaque a seguinte particularidade: embora os valores médios de todas as transações possam ser elevados na fase recessiva, o facto é que tanto os valores das propriedades rurais como das propriedades de uso misto caíram em comparação com os valores registados na fase de expansão do ciclo imobiliário (Figura 2). Naturalmente, isto também prova a teoria de que a queda dos valores do solo é mais acentuada nas áreas periféricas do que nas áreas centrais: "Hoyt confirmou a hipótese de que os valores do solo atingem um pico imediatamente antes do início da depressão $e$ também revelou os diferentes padrões dentro da cidade (...) Os dados mostram claramente que os valores do solo modificam-se nas áreas periféricas durante as fases do "boom" - não é em toda a cidade, enquanto numas áreas existe um ritmo elevado de alteração, através da anexação de solo rural, outras tendem a perder valor devido à obsolescência das estruturas edificadas - e contrai mais severamente nestas áreas depois do "crash". Então, os valores do solo no centro de negócios não chegaram a duplicar entre 1910 e 1928, mas o solo 
destinado a habitação e construção de instalações empresariais na periferia cresceram tendo como base um fator de 4.5 e 6.7 respetivamente. O "crash" subsequente era muito maior nas periferias. Isto mostra que a volatilidade dos preços do solo está em áreas novas desenvolvidas em solos periféricos" (Hoyt, 1933: 347 citado por Gaffney, 2015: 338).

Ainda assim a atual manutenção de valores do solo elevados (apesar da descida em relação aos preços médios de 2007 e 2008) é o reflexo dos subsídios existentes para a compra de imobiliário por parte de especuladores (Fundos de Investimento Imobiliário) e por investidores ou residentes estrangeiros. Por exemplo, destacar apenas que a Lei n.․ 75$\mathrm{A} / 2014$, de 30 de setembro (Estatuto dos Benefícios Fiscais) permite que os Fundos de Investimento Imobiliário paguem apenas metade do imposto sobre a propriedade e do imposto sobre as tramitações onerosas de imóveis (de acordo com as disposições regulamentares incluídas no capítulo VI denominado: Incentivos Fiscais ao Investimento Produtivo). Os Vistos Gold (PLMJ, 2015) correspondem a outro instrumento legislativo que subsidia o investimento imobiliário, em particular através da regulação do investimento estrangeiro, nomeadamente no que se refere à compra de imóveis com valor igual ou superior a 500.000,00€. Estes subsídios tendem a estar centrados sobre uma procura com elevado nível de rendimentos, que é a única que consegue operar numa situação de congelamento de mercado (após o colapso da bolha e sem requerer grandes quantidades de capital alheio) (Fisher, 1951). Por sua vez, este tipo de procura, adquire a maioria dos imóveis nas grandes cidades (Lisboa e numa menor extensão também no Porto), os palacetes e os apartamentos de luxo na Costa do Sol (Municípios de Oeiras e Cascais), moradias em "resorts" e apartamentos de luxo situados numa das principais regiões turísticas de Portugal como o Algarve. Esta sequência de subsídios leva à concentração de elevados fluxos de capital em poucas áreas e num número muito restrito de propriedades, que pode gerar conclusões erradas acerca do nível médio de preços no mercado imobiliário. A confirmação da observação anterior é dada pelo número de propriedades transacionadas (INE, 2015b): (i) durante a fase de expansão, o número médio de transações foi de 73.509 por ano, enquanto na fase recessiva (incluindo os anos de 2013 e 2014), este número cai para 38.298 transações anuais (uma queda de 47,90\%, equivalente a aproximadamente metade do número de transações verificadas no registo anterior); (ii) o número médio de transações de propriedades rurais caiu $65,44 \%$ entre estes dois períodos, o de propriedades urbanas caiu 46,99\%; e o de imóveis de uso misto caiu 59,04\%. Estes números suportam a tese da bolha imobiliária e o momento em que esta rebenta (entre 2007 e 2008). Nesta escala, embora os valores médios das transações não se tenham mantido em baixa durante muitos anos, devido às razões avançadas, o facto é que o número de transações não só caiu abruptamente como se mantém com um fluxo muito abaixo da média registada durante a fase de expansão do ciclo imobiliário: o mercado está congelado, porque o crédito não está 
disponível, devido a uma crise de liquidez dos bancos gerada precisamente pela bolha imobiliária. As transações são muito restritas e cobrem apenas um conjunto limitado de agentes (estão estruturadas no segmento do mercado com elevados rendimentos).

\subsection{A Escala da Cidade de Lisboa}

A cidade de Lisboa já ultrapassou os limites administrativos do Município. A observação de imagens de satélite recentes sobrepostas pelos limites administrativos do Município de Lisboa confirma este facto. O critério da observação deve ser a continuidade do tecido urbano. Este método chega para fundamentar este raciocínio, no entanto, esta é uma análise que merece aprofundamento empírico. Só com este tipo de abordagem seria possível identificar uma unidade territorial consistente com os limites da cidade de Lisboa (estes limites abrangem subúrbios, vilas e até cidades metropolitanas) que o autor defende, tendo como raciocínio de base, a teoria da escassez artificial. No entanto, mesmo com a configuração da unidade territorial devidamente definida, não existiria a informação necessária para validar a bolha imobiliária através da perspetiva do valor do solo. Face a estas limitações, a escala da cidade de Lisboa analisada neste trabalho está limitada à área administrativa do Município, que não corresponde de todo aos limites reais da cidade.

A informação trabalhada nos subcapítulos anteriores mostra que os picos do preço do imobiliário ocorreram em 2007 e 2008. Em 2007, os valores do solo chegam a um pico e a bolha colapsa durante o ano de 2008. A informação de base que permite evidenciar o acontecimento é o valor médio das propriedades transacionadas apoiada sempre que necessário pelo número de propriedades transacionadas. Na sequência do processo de desagregação que tem vindo a ser realizado ao longo deste trabalho, é a vez de avançar para a escala local e a melhor informação para evidenciar a bolha imobiliária nesta escala deve ser coincidente com a informação representativa das cidades. Logo se a cidade de Lisboa já ultrapassou os limites do Município, então o próprio Município de Lisboa corresponde a uma unidade estatística relevante para explicar e comprovar a tese da bolha imobiliária.

Na sequência do raciocínio anterior, a Figura 3 apresenta a confirmação desta tese: entre 2000 e 2008, o valor médio de todos os tipos de propriedades transacionadas aumentou 103\% (mais do que duplicou), mas o pico nem foi em 2008. O pico do valor médio das propriedades transacionadas cobrindo todo o tipo de imobiliário (propriedades urbanas, rústicas e mistas) foi atingido em 2007. Assim sendo, considerando os anos entre 2000 e 2007, os valores médios dos imóveis aumentaram 133\%. O valor das propriedades urbanas subiu $132 \%$. Nas propriedades rurais, o crescimento atingiu os $360 \%$ e nas propriedades de uso misto chegou aos 347\%. De 2007 a 2008, o valor médio dos imóveis caiu 11,82\% nas 
propriedades urbanas, $81,76 \%$ nas propriedades rurais e $79,27 \%$ nas propriedades de uso misto. Como um todo, os valores dos imóveis transacionados caíram 13,02\% em apenas um ano. Entre 2007 e 2012, os valores dos imóveis caíram 30,36\%: os imóveis urbanos caíram $30,49 \%$ e as propriedades de uso misto caíram $32,16 \%$. Em sentido inverso as propriedades rurais subiram $73,01 \%$.

Esta aparente contradição pode ser explicada pela baixa representatividade das propriedades rurais e de uso misto no total de imóveis transacionados a esta escala. 0 contexto descrito demonstra que a maioria do volume de transações registado nesta escala corresponde às propriedades urbanas, que comandam as flutuações gerais do mercado imobiliário: para todos os anos para os quais existe registo, as transações de imóveis urbanos representam $99,73 \%$ do volume total de transações de imóveis.

As alterações abruptas no volume e no valor dos imóveis estão diretamente relacionadas com o valor do solo: este afeta o preço das propriedades urbanas e desta forma também o nível geral de preços, no entanto, é nas propriedades rurais que o valor do solo se confunde quase por inteiro com o preço do imóvel, até porque estas propriedades quando inseridas no interior dos limites da cidade (como é o caso), estão geralmente subaproveitadas (abandonadas ou longe da sua melhor utilização), logo o valor do capital corresponde apenas a uma pequena fração do preço dos imóveis.

O impacto do valor do solo à escala urbana pode ainda ser confirmado pelos seguintes elementos (dados de 2000 a 2014): (i) à escala local, o valor médio das propriedades rurais transacionadas é superior ao valor médio das propriedades urbanas em 2,5 vezes; (ii) também à escala local, o valor médio das propriedades de uso misto é superior ao valor médio das propriedades urbanas em cerca de 4 vezes; (iii) o valor médio das propriedades rurais transacionadas em Lisboa é 25 vezes superior ao valor médio do mesmo tipo de propriedades em Portugal e 3,5 vezes maior do que o valor médio das transações à escala metropolitana; e (iv) o valor médio das propriedades de uso misto transacionadas em Lisboa é 5,5 vezes superior ao valor médio do mesmo tipo de propriedades à escala nacional e maior do que o dobro do valor médio deste tipo de imóveis na Área Metropolitana de Lisboa. 


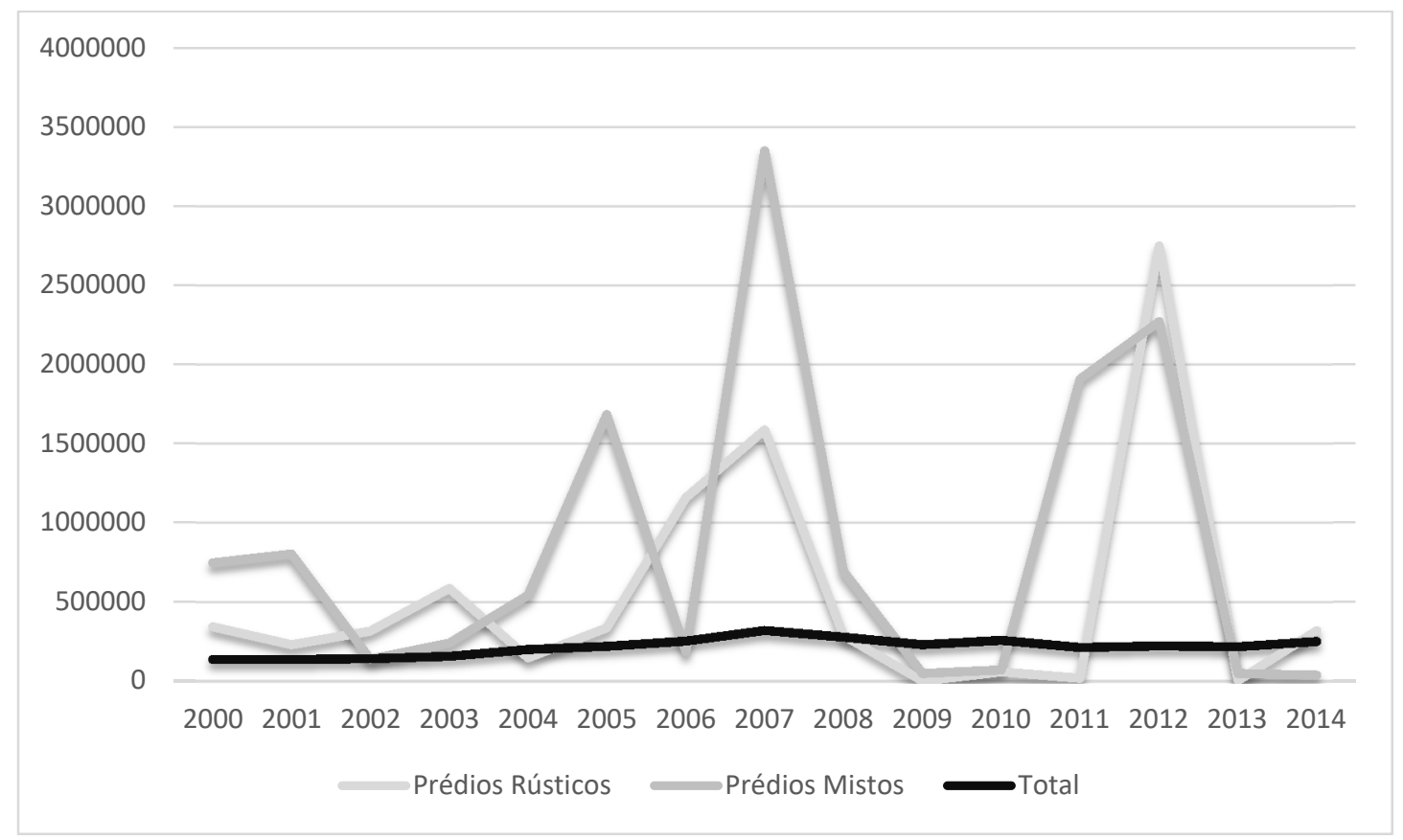

Figura 3 - Valor Médio (€) dos Contratos de Compra e Venda de Imobiliário situados em Lisboa (2000-2014)

Fonte: Adaptado de INE (2015a)

Esta confirmação da sobrevalorização do solo num curto período de tempo reforça a validação da hipótese da bolha imobiliária. A relação entre os dados obtidos para as diferentes escalas (agregada ou nacional, regional e local) permite extrapolar que a política fiscal concede elevados subsídios ao sector imobiliário. Além disso, a distribuição dos subsídios não é minimamente equitativa. Os proprietários de imóveis rústicos e de imóveis de uso misto (urbanos e rústicos) situados em áreas próximas ou dentro dos próprios limites das cidades são os maiores beneficiários do atual sistema de tributação. Esta é a única explicação para a diferença registada entre os valores médios das propriedades urbanas e os valores médios tanto das propriedades rústicas como das propriedades mistas em pelo menos duas dimensões: (i) na escala nacional e regional, comparando o mesmo tipo de propriedade; e (ii) na escala local, relacionando os diferentes tipos de propriedade.

A falha do modelo de tributação existe porque as propriedades são classificadas para efeitos fiscais apenas como propriedades rurais ou propriedades urbanas (as propriedades mistas são a designação utilizada para classificar as propriedades onde não é possível distinguir se o principal uso do solo é o urbano ou o rural). A classificação dos imóveis (distinção entre urbanos e rústicos) gera dois sistemas de avaliação do valor patrimonial: um para cada tipo 
de propriedade. Os imóveis urbanos são avaliados com base no valor dos melhoramentos (estruturas edificadas), enquanto as propriedades rústicas são avaliadas conforme o seu valor de rendimento através de uma utilização rural produtiva (plantações). Logo se as propriedades estão dentro da cidade, apenas nos casos em que o solo não pode ser transformado em usos urbanos (pequenas parcelas com dimensão obsoleta, onde o processo de construção não é viável devido à dimensão do lote - estes casos podem apesar de tudo ser transformados em solo urbano através de processos de reestruturação urbanística ou através de projetos de alargamento ou desenvolvimento de novos espaços públicos - e solo situado em leito de cheia) é que estas propriedades têm um valor de mercado próximo do valor de avaliação para efeitos fiscais. Contudo, o Plano Diretor Municipal de Lisboa (Câmara Municipal de Lisboa, 2012) confirma que todo o solo dentro das fronteiras administrativas do Município corresponde a solo urbano (dentro desta classificação, existem várias categorias de uso do solo sub-classificadas como solo alocado para usos recreativos ou espaços verdes, mas provavelmente a maioria deste solo, mesmo que uma parte ainda não tenha sido transformado de acordo com o previsto, já é propriedade do Município ou do Estado). Assim se demonstra que existe incompatibilidade entre a política fiscal e a política de ordenamento do território. Se o solo é classificado como urbano (apto para urbanização) e este permanece classificado como solo rústico pela política fiscal, a situação gera um enorme subsídio: as Figuras 4 e 5 ilustram alguns destes tipos de propriedade que são considerados como imóveis urbanos pela política de ordenamento do território, mas que provavelmente são classificados como rústicos para efeitos de avaliação fiscal. Os proprietários de imóveis, que beneficiam desta dualidade de critérios de classificação e que estão inseridos em áreas dentro ou próximas dos limites das cidades, vilas ou outro tipo de povoamento onde o valor do solo é elevado o suficiente para promover a sua transformação em solo afeto a usos urbanos, acabam por ser altamente subsidiados. Provavelmente esta questão poderia ser reportada, se o País tivesse um cadastro completo e atualizado, o que não é o caso de Portugal.

Outro elemento que explica a sobrevalorização do imobiliário é a frequência das avaliações patrimoniais, que é muito lenta - de 3 em 3 anos para a maioria dos prédios urbanos, segundo a aplicação do critério dos $75 \%$ do coeficiente de desvalorização monetária, ocorrido durante cada período; é anual no caso de propriedades industriais ou comerciais, 
conforme o mesmo critério; não existe qualquer referência para os prédios rústicos (Autoridade Tributária e Aduaneira, 2013). Deste modo, durante a fase de expansão do ciclo imobiliário, os imóveis beneficiam de um tratamento fiscal favorável, o que acaba por ajudar à própria euforia/irracionalidade do mercado comprovada pela análise numérica desenvolvida neste trabalho.

Face a este contexto, existe um bloqueio ao desenvolvimento do solo vazio, porque, por exemplo, no caso de Lisboa, este só é acessível a um número muito limitado de indivíduos (ou famílias) e grandes empresas que têm um nível de rendimentos líquidos suficientemente elevado para conseguir adquirir o solo disponível na cidade. Porém, uma parte destes agentes são especuladores imobiliários, que optam por reter a propriedade, por tempo indefinido, abstendo-se de investir no seu desenvolvimento e abdicando da sua utilização. O outro grupo de agentes pode investir na construção/remodelação de estruturas edificadas, porém estas acabam por ser inacessíveis (pelos preços de venda ou arrendamento) para a maioria da procura efetiva.

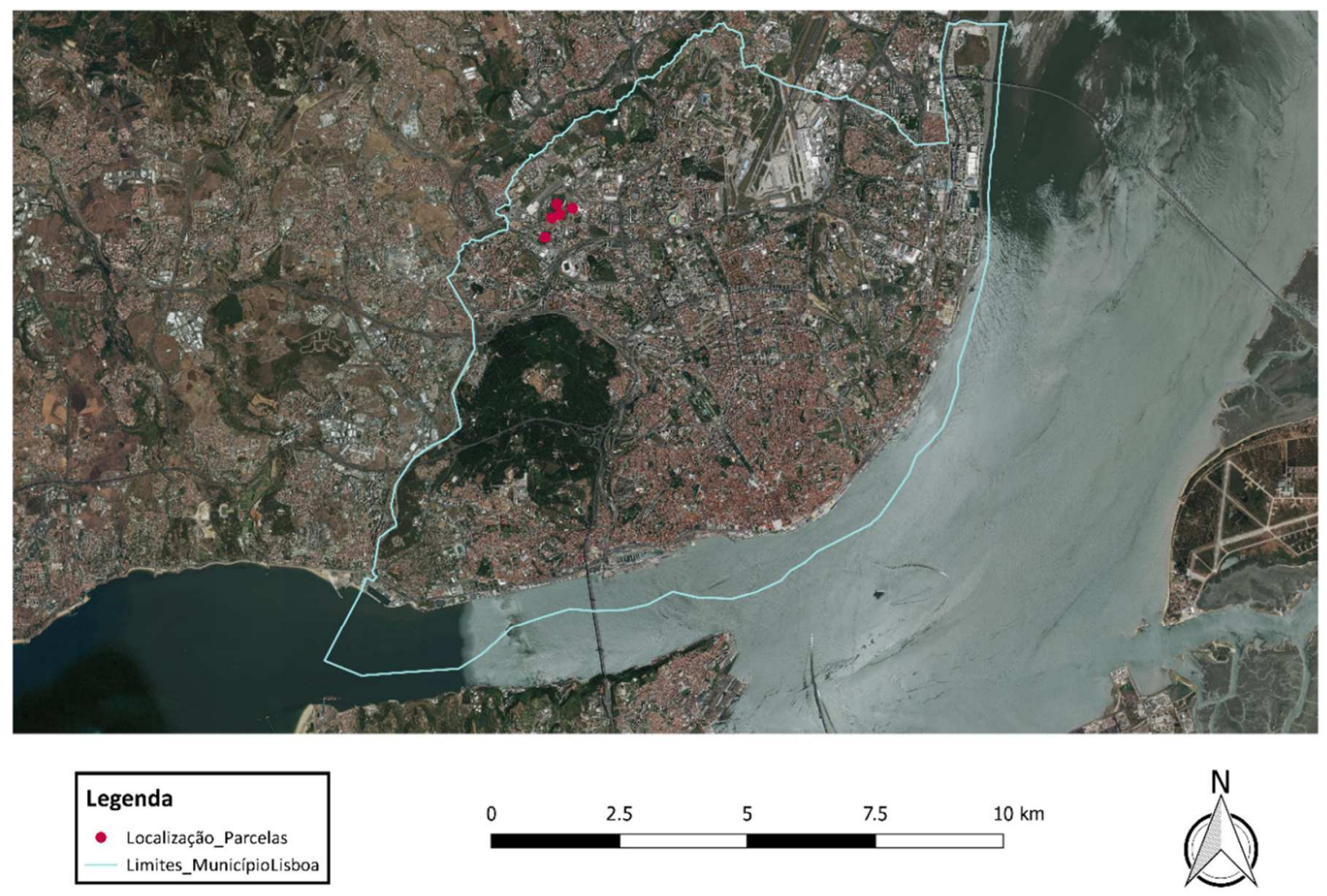

Figura 4 - Localização de Pequena Amostra de Parcelas de Solo Vazio em Carnide, Município de Lisboa

Fonte: Autor (2017). 

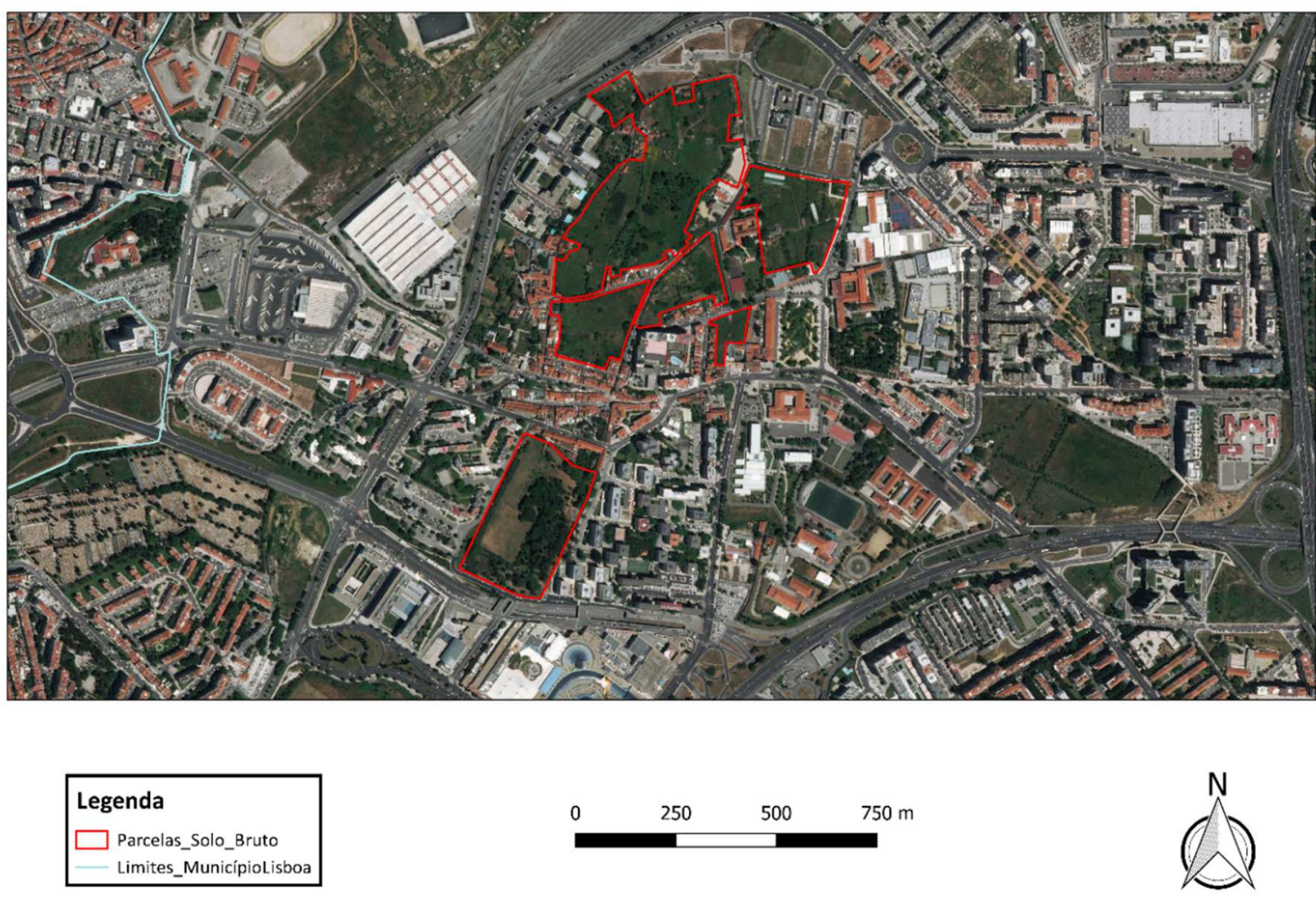

Figura 5 - Identificação e Delimitação da Amostra de Parcelas de Solo Vago no Bairro de Carnide, Lisboa

Fonte: Autor (2017).

As conclusões acerca da informação disponível para descrever as dinâmicas do mercado imobiliário ainda não estão esgotadas (INE, 2015b): (i) comparando o volume de transações de todos os tipos de propriedade em Lisboa (Município) com o mesmo indicador à escala regional, verifica-se que em 2000, o volume de propriedades transacionadas representou apenas $16,12 \%$ do volume total de imóveis transacionados na Área Metropolitana de Lisboa, enquanto em 2014, este indicador aumentou para 31,77\%. Este elemento confirma o argumento de que durante a fase de congelamento do mercado (após o rebentamento da bolha imobiliária), o dinamismo do mercado está centrado nas movimentações dos operadores com elevados rendimentos (tanto do lado da oferta como da procura). Além de beneficiarem dos subsídios acima mencionados, estes são operadores com liquidez, ou seja, estão pouco dependentes do crédito (Fisher, 1951). As transações existentes cobrem maioritariamente as propriedades situadas nas "áreas prime" da cidade: Parque das Nações, Avenida da Liberdade, Baixa Pombalina e Saldanha. Por sua vez, esta situação também explica o elevado valor médio dos imóveis transacionados no período após o rebentamento da bolha, embora se verifique que estes ainda apresentam valores inferiores aos registados durante o pico de 2007 e até dos valores de 2008; (ii) em média, o número de propriedades transacionadas por ano durante a fase de expansão do ciclo imobiliário (2000-2008) foi de 
15.155 e na fase de recessão foi de 9.272. Portanto, confirma-se que numa base anual, existe uma quebra de 5.882 transações entre os dois períodos ou uma queda de $38 \%$ no volume total de transações de imóveis situados dentro dos limites administrativos de Lisboa. Apesar destes números, a queda do volume de transações de imóveis entre os dois períodos do ciclo imobiliário nesta área é inferior à queda registada na escala regional (da Área Metropolitana de Lisboa).

\section{Conclusões}

Os números analisados indicam que, efetivamente, existiu uma bolha imobiliária em Portugal, contrariando os resultados obtidos noutras abordagens desenvolvidas sobre este tema (Fradique Lourenço e Rodrigues, 2014). Associado a este fenómeno está o termo "euforia". A euforia corresponde a um nível excessivo de confiança que se baseia sobretudo nas tendências do passado (ou de acontecimentos propagandeados) mais do que na racionalidade ou na qualidade das opções de investimento (Glaeser, 2013; Greaney, 2015). Se as avaliações dos imóveis para efeitos fiscais acompanhassem as valorizações anuais do mercado, provavelmente, a subida dos preços numa base anual acabaria por ser menor. Sem prejuízo deste facto, a mera atualização do valor patrimonial não impede a formação de uma bolha imobiliária, porque os critérios adotados na fórmula de cálculo deste valor podem produzir diferenças significativas entre os valores da propriedade para efeitos fiscais e os valores de mercado dos imóveis (Carvalho, 2014; Henriques, 2015). No caso português, existem diferenças na fórmula consoante o tipo de classificação do solo (para efeitos fiscais): rústico ou urbano. Portanto, são utilizadas duas fórmulas distintas para calcular o mesmo valor, em função do uso dominante da propriedade. Este elemento apenas comprova que o valor de mercado dos imóveis raramente coincide com os valores calculados para efeitos fiscais.

Em síntese, este trabalho oferece uma primeira validação da tese da bolha imobiliária: os preços dos imóveis (ativos imobiliários) subiram, de forma significativa, num curto espaço de tempo (2000-2007), caindo abruptamente a partir de 2008. Para além da análise da evolução do preço a uma escala agregada, foi desenvolvido um trabalho de desagregação com base na informação estatística disponível, até à escala do Município. Neste âmbito e para demonstrar a preponderância dos elementos especulativos (sobretudo associados aos diferentes níveis de produtividade que é possível alcançar através do possível desenvolvimento do solo urbano) na dinâmica do próprio ciclo imobiliário, o trabalho foi centrado no Município de Lisboa. 
Com a aplicação destas duas abordagens foi possível confirmar os elementos que alimentam a bolha imobiliária e aprofundar os fatores predominantes que estão na génese deste fenómeno: aumentos de produtividade do solo urbano; reforço da proximidade e investimento em melhoramentos das redes de ligação física entre áreas povoadas; distribuição da propriedade do solo; subsídios atribuídos pela política fiscal.

Para o futuro, esta investigação salienta a importância de concluir a aplicação do modelo económico que forneceu a base para este trabalho, pois para além da formação do preço, será possível alargar o conhecimento acerca da bolha imobiliária aos seguintes domínios: (i) território, onde o teste é perceber onde se concentraram os fluxos do investimento em imobiliário (atendendo a uma relação entre áreas periféricas e centrais) e que razões explicam esse processo; (ii) económico-empresarial, através de uma análise acerca dos reflexos da dinâmica especulativa sobre a evolução dos diferentes sectores de atividade económica; e (iii) financeira, onde se procurará relacionar a origem dos elevados níveis de endividamento com as dinâmicas do mercado imobiliário, como hipótese de base para a origem da crise de liquidez dos bancos. Este conhecimento é relevante para se perceber o que é que falhou na sociedade portuguesa e para se compreender as razões por detrás da longa-duração da crise económica, fornecendo, ao mesmo tempo, uma base sólida para preparar mudanças em diferentes domínios, desde logo, ao nível da Política de Ordenamento do Território e da Política Fiscal.

\section{Referências bibliográficas}

\section{Artigos científicos}

AALBERTS, Manuel, Geographies of the financial crisis, Area, Vol 41, No.1, 2009, pp. 34-42.

ARELLANO, Manuel; BENTOLILA, Samuel, La Burbuja Inmobiliaria: causas y responsables, Centro de Estudios Monetarios y Financieros, 2009, Última consulta em 15/03/2017, disponível em http://crisis09.fedea.net/ebook/la-burbuja-inmobiliaria.html.

AUTORIDADE TRIBUTÁRIA E ADUANEIRA, Código do Imposto Municipal sobre Imóveis, 2013, Última consulta em 19/03/2016, disponível em http://info.portaldasfinancas.gov.pt/pt/informacao_fiscal/codigos_tributarios/cimi/index_cimi.htm.

BINGRE DO AMARAL, Pedro, Análise da relação das políticas de solos com o sistema económico, Estudo de Enquadramento para a Preparação da Nova Lei do Solo, DGOTDU, 2011, Última consulta em 25/02/2017, disponível em http://www.forumdascidades.pt/sites/default/files/lds_estudos-2011_pbingre_politica-solos-esistema-economico_0.pdf.

BRENNER, Neil; SCHMID, Christian, Towards a new epistemology of the urban?, City, Vol 19, No. 2-3, 2015, pp. 151-182.

CARVALHO, João M., Algoritmos universais de perequação - uma abordagem exploratória, Seminário Modelos de Financiamento de Operações Urbanísticas: Desafios e Oportunidades, Instituto Superior Técnico, 2014, 
Última consulta $\quad$ em $13 / 04 / 2017, \quad$ disponível em http://projectopercom.tecnico.ulisboa.pt/pdf/docs/WorkshopPERCOM_2_JMC.pdf.

CML - Câmara Municipal de Lisboa, Regulamento do PDM, Lisboa: Câmara Municipal de Lisboa, 2012, Última consulta em 05/04/2016, disponível em http://www.cmlisboa.pt/fileadmin/VIVER/Urbanismo/urbanismo/planeamento/pdm/AF_REGULAMENTO_PDM_Lx.pdf.

DELGADO VIÑAS, Carmén, Secuelas territoriales de la «burbuja inmobiliaria» en las áreas protegidas litorales españolas, Ciudad y Território: Estudios Territoriales (CyTET), Vol XLIV (174), 2012, pp. 615-637.

ETXEZARRETA ETXARRI, Aitziber; HOEKSTRA, Joris; DOL, Keel; CANO FUENTES, Gala, De la burbuja inmobiliaria a las ejecuciones hipotecarias, Ciudad y Território: Estudios Territoriales (CyTET), Vol XLIV (174), 2012, pp. 597613.

FISCHEL, William, The Evolution of Zoning since the 1980s: the persistence of localism, in COLE, D. and HOSTROM, E. (eds), Property in Land and Other Resources, Massachusetts - Cambridge: Lincoln Institute of Land Policy, 2012, pp. 259-287.

FISHER, Ernest M.,Urban Real Estate Markets, Characteristics and Financing, Cambridge (MA): National Bureau of Economic Research, 1951.

FOLDVARY, Fred, The Depression of 2008, Berkeley (CA): Gutenberg Press, $2^{\text {nd }}$ Edition, 2007.

FOLDVARY, Fred, Real Estate Bubble, The Progress Report, 2004, Última consulta em 08/03/2017, disponível em http://progress.org/tpr/foldvary-the-real-estate-bubble/.

FRADIQUE LOURENÇO, Rita; RODRIGUES, Paulo M. M., Dinâmica e contraste dos preços da habitação em Portugal e Espanha, Boletim Económico do Banco de Portugal, 2014, Última consulta em 10/03/2017, disponível em https://www.bportugal.pt/sites/default/files/anexos/papers/ab201413_p.pdf.

FUNDÁCION ALTERNATIVAS, Urbanismo y Democracia: Alternativas para evitar la corrupción, Madrid: Fundación Alternativas, Última consulta em 23/03/2017, disponível em http://www.fundacionalternativas.org/public/storage/publicaciones_archivos/xmlimport-fL5JRu.pdf.

GAFFNEY, Mason, A real-assets model of economic crises: Will China crash in 2015?, American Journal of Economics and Sociology, Vol 74, Issue 2, 2015, pp. 325-360.

GAFFNEY, Mason, After the Crash: Designing a Depression-Free Economy, Chichester (UK): Wiley-Blackwell, 2009.

GAFFNEY, Mason, The Role of Ground Rent in Urban Decay and Revival: How to Revitalize a Failing City, in COBB, C. and GIACALONE, J. (eds), The Path to Justice. Malden, MA and Oxford Publishers: Blackwell Publishers, 2001, pp. 57-84.

GEORGE, Henry, Progress and Poverty, New York: Cambridge University Press, 2009 [1881].

GLAESER, Edward. L., A Nation of Gamblers: Real Estate Speculation and American History, American Economic Review: Papers and Proceedings, Vol 103, Issue 3, 2013, pp. 1-42.

GREANEY, Michael D., The Business Cycle: a Kelsonian Analysis, American Journal of Economics and Sociology, Vol 74, Issue 2, 2015, pp. 379-418.

HARRISON, Fred, Boom Bust: House Prices, Banking and Depression of 2010, London: Shepheard-Walwyn (Publishers) Ltd, 2010 [2005].

HENRIQUES, João, As Dinâmicas do Mercado Imobiliário e os Impactos Territoriais, Lisboa: Chiado Editora, 2015.

HOEKSTRA, Joris; VAKILI-ZAD, Cyrus, High vacancy-rate and rising housing price: the Spanish Paradox, Tijdschrift voor Economische en Sociale Geografie, Vol 102, Issue 1, 2011, pp. 55-71.

HOYT, Homer, One hundred years of land values in Chicago, Illinois - Chicago: The University of Chicago Press., 1933.

INE, Estatísticas Históricas Portuguesas, Lisboa: Instituto Nacional de Estatística, 2001. 
LOPEZ GARCIA, Miguel A., Precios inmobiliarios, renta y tipos de interes en España, Instituto de Estudos Fiscales, 2004, Última consulta em 23/03/2017, disponível em https://dialnet.unirioja.es/descarga/articulo/3136001.pdf.

PLMJ. Golden Visa: As novas condições e requisitos para obtenção e renovação de autorização de residência para investimento em Portugal, Newsletter, 2015, Última consulta em 09/08/2016, disponível em http://www.plmj.com/xms/files/newsletters/2015/Setembro/As-Novas-Condicoes-e-Requisitos-para-aObtencao-de-Golden-Visa.pdf.

RODRIGUÉZ LÓPEZ, Julio, Debilidad de la economia, debilidade del mercado de vivenda, Ciudad y Território: Estudios Territoriales (CYTET), Vol XLIV (174), 2012, pp. 763-776.

ROMERO, Juan; JIMENEZ, Fernando; VILLORIA, Manuel, (Un)Sustainable Territories: Causes of the Speculative Bubble in Spain (1996-2010) and its Territorial, Environmental, and Sociopolitical Consequences, Environment and Planning C: Politics and Space, Vol 30, Issue 3, 2012, pp. 467-486.

SUMNER, Scott, What would Milton Friedman have thought of the Great Recession?, American Journal of Economics and Sociology, Vol 74, Issue 2, 2015, pp. 209-235.

\section{Normas}

Lei n. 75-A/2014 de 30 de setembro, Diário da República no188 - 1ạSérie, Assembleia da República.

\section{$\underline{\text { Indicadores Estatísticos }}$}

INE - Instituto Nacional de Estatística, Valor médio dos prédios transacionados por localização geográfica e tipo de prédio, Anual - Direção Geral da Política de Justiça, 2015a.

INE, Número de prédios transacionados por localização geográfica e tipo de prédio, Anual - Direção Geral da Política de Justiça, 2015b.

INE, População (№) por local de residência, sexo e grupo etário, Anual - INE, Estimativas Anuais da População Residente, 2015c.

INE, Superfície $(\mathrm{km} 2)$ das unidades territoriais por localização geográfica, Anual - INE, Instituto Geográfico Português, 2015d.

INE, Densidade Populacional (№/km2) por local de residência, Anual - INE, 2015e.

INE, Superfície $(\mathrm{km} 2)$ das unidades territoriais por localização geográfica, Decenal - INE, Recenseamento da População e Habitação, $2015 f$.

INE, Densidade Populacional (№/km2) por Local de residência, Decenal - INE, Recenseamento da População e Habitação, 2015g.

INE, Cidades (№) por localização geográfica, Anual - INE, Sistema Integrado de Nomenclaturas Estatísticas, 2016. 